\title{
Estimates of past and future time trends in age-specific breast cancer incidence among women in Karachi, Pakistan: 2004-2025
}

\author{
Sidra Zaheer ${ }^{1,2^{*}}$, Nadia Shah², Syed Amir Maqbool ${ }^{3}$ and Noor Muhammad Soomro ${ }^{4}$
}

\begin{abstract}
Background: The current demographic trends indicate that breast cancer will pose an even greater public health concern in future for Pakistan. Details on the incidence, disease severity and mortality in respect of breast cancer are limited and without such data, therefore, future health policies or systems in respect of this disease cannot be strategically planned or implemented. The aim of this study was to examine past trends of age-specific breast cancer incidence rates (2004-2015), and to estimate the future volume of breast cancer cases in Karachi through the year 2025.
\end{abstract}

Methods: Two statistical methods, namely the functional time series models and the log-linear regression model were used; additionally, their real forecasting efficacy in epidemic time series was also evaluated.

Results: In the past, women aged 60-64 years had the highest overall breast cancer incidence rates, while from 2016 to 2025, large increases in breast cancer rates among women aged 50 to 64 years are expected. The total projected breast cancer incidence will increase by approximately $23.1 \%$ in 2020 to $60.7 \%$ in 2025. Cases of breast cancer diagnosed in younger women, aged 30-34 years, will increase from 70.7 to $130.6 \%$ in 2020 and 2025 relative to 2015.

Conclusions: The breast cancer incidence appeared to have been rising more rapidly among post-menopausal women (aged 55 to 59), while a stable increase in incidence in the youngest age group (15-29years) of women is expected. The results also infer an expected increase in incidence cases of breast cancer among middle aged women in Karachi, Pakistan. An increase in the number of incident cases of cancer has implications for understanding the health-care needs of growing population and the subsequent demands on health-care system.

Keywords: Breast cancer incidence, Forecasting, Functional time series model, Log-linear regression model

\section{Background}

Globally, 2.4 million newly diagnosed female breast cancer cases are predicted on the basis of demographic changes only, accounting for almost 1 in 4 cancer cases among women in 2018 [1,2]. Although, the incidence of breast cancer in Asia is still lower than that in Western countries, in the modern epoch, the proportional contribution to the global burden of breast cancer is growing rapidly in Asia [2]. This has mainly contributed to recent initiatives such as the establishment of breast cancer

\footnotetext{
* Correspondence: sidra.zaheer@duhs.edu.pk

${ }^{1}$ Department of Statistics, University of Karachi, Karachi, Pakistan

${ }^{2}$ School of Public Health, Dow University of Health Sciences, OJHA Campus,

Suparco road, Karachi, Pakistan

Full list of author information is available at the end of the article
}

registries. The risk of having breast cancer has increased in Pakistan, whereby one in every 9 women in Pakistan has a lifetime risk of being diagnosed with breast cancer [3]. The age-standardized incidence rate of breast cancer in Pakistan is one of the highest among Asian countries [4]. Unfortunately, the rate of deaths due to breast cancer is also higher in the country, due to late diagnosis and delayed referral to appropriate facilities [5]. Hence, early diagnosis and therefore early management of breast cancer can progress the survival rate. The situation is worst in Pakistani women where the number is more than that and no systemic and scientific approach has been employed to combat the situation. The accurate occurrence, number of new cancer cases, death rates, 
and casualty rate annually for Pakistan are not documented. No comprehensive registries/database existing regarding any disease as well as breast cancer in Pakistan and the only data on hand is hospital based [6].

With the recent advent of modern screening techniques and extended age range for screening, a large disparity in age-adjusted incidence rates has emerged. It has been observed that in Western countries, the rate increases rapidly before menopause, and then increases gradually afterward [1]. The recent increase in breast cancer incidence in Western countries is most apparent in women aged 50 years and older [7]. On the other hand, accumulating data from the developing world suggest substantially higher proportion $(47.3 \%)$ of all incident breast cancers among pre-menopausal aged compared to older women [8]. Majority of Asian populations display a peak in breast cancer incidence between 40 and 59 years of age; particularly, the peak age-specific incidence rate of breast cancer in India, Korea and Japan are 50-59, 40-49 and 45-54 years respectively [8-10]. Whereas the peak age in Sri Lanka is seen among women aged 60-64 years [11].

The current demographic trends indicate that breast cancer will pose an even greater public health concern in future for Pakistan. Additionally, there is a paucity of information regarding breast cancer in Pakistan [12]. Predictions have been used to advocate the allocation of adequate resources for diagnosis and treatment of disease [13-15]; however, there is little progress on the subject matter in recent times. These call for enhanced focus on research in the area of breast cancer, in order to generating accurate data.

The aim of the present study is to examine past trends of age-specific breast cancer incidence rates among Pakistani women aged > 15 years; and to estimate the future volume of breast cancer cases in Pakistan through the year 2025. Since we are primarily interested in having predictions that are accurate, thus, to achieve this objective, two statistical methods, namely the functional time series (FTS) models and the log-linear regression (LLR) model are applied. Further, their real forecasting efficacy in epidemic time series was also evaluated.

\section{Methods}

\section{Study settings}

Karachi is the largest metropolitan area in Pakistan with a population of approximately 16 million [16]. Breast cancer cases from neighboring districts/ provinces are referred to the major tertiary care facilities established in the city. Jinnah Post Graduate Medical Centre (JPMC), Karachi Institute of Radiotherapy and Nuclear Medicine (KIRAN) hospital and Civil Hospital, Karachi (CHK) are well established in the diagnosis and treatment of cancer patients. Majority of the population of Karachi and interior Sindh, needing cancer treatment, visit one of these centers for their respective cancer treatment. Thus, at present these institutes provide a comprehensive collection of all breast cancer cases in the Sindh region. The data used in this study were collected from these three centers. Although this is a hospital based data, and therefore have some constraints and biases, it is the major source, which can provide essential clinical, administrative and educational information on breast cancer incidence and allow for the estimation of national pattern in the absence of any population based cancer registry in the country [17].

\section{Study population}

A total of 9771 registered diagnosed cases of female breast cancer during the period 2004 to 2015 were included; however, the cases with missing age and duplicate information were excluded in the study. The diagnosis of each patient was according to the international classification of diseases-oncology.

\section{Estimated age-specific women population, Karachi- Pakistan: 2004-2025}

Based on the 1998 census, data on the age-specific female mid-year population of Karachi, Pakistan was obtained from the Pakistan Bureau of Statistics-Sindh, for all six districts of Karachi [16]. Using 1998 census women data, future estimates of age-specific women population for the years 2004-2025 were estimated using Age-Specific Growth Rate (ASGR) [18]. To estimate the future population, following mathematical formula was used:

$$
P_{t}=B * e^{r * t}
$$

Here, $\mathrm{P}=$ population at a future time, $\mathrm{B}=$ population at base census, $\mathrm{e}=$ base of natural logarithm (2.71828), $\mathrm{r}=$ growth rate, and $\mathrm{t}=$ time period in years between future and base population [19].

\section{Past and future trends of age-specific incidence rates of breast cancer: 2004-2025}

Past trends of age-specific women breast cancer incidence rates from 2004 to 2015 were calculated as the number of new cases of breast cancer divided by the corresponding population at risk during a year, expressed as the rates per 100,000 persons per year $[4,20]$.

For future trends (2016-2025), the age-specific breast cancer incidence rates were estimated using FTS models [4, 21] and LLR model [22, 23]. Past and future estimates were reported for each age group (15-19, 20-24, 25-29, 30-34, 35-39, 40-44, 45-49, 50-54, 55-59, 60$64,65-69,70-74,75+)$. For each of the forecasting 
method, we have shown the obtained forecast diagrams which graphically depict the closeness between the original and forecasted incidence rates (Additional file 1: Figure S1 and S2).

\section{Functional time series (FTS) models}

FTS models were recently developed by Hyndman and Ullah 2007 for demographic projections [24]. These models were also applied to the breast cancer mortality rates by Erbas et al. and Yasmeen et al. [21, 25, 26]. To predict future estimates, these models treated incidence rates as a continuous function of age curves. For each curve, the log incidence rates were also obtained separately as follow:

$$
y_{t}\left(v_{i}\right)=s_{t}\left(v_{i}\right)+\sigma_{t}\left(v_{i}\right) \varepsilon_{t, i}
$$

Where $y_{t}(v)=\log \left[r_{t}(v)\right]$. Thereafter, the nonparametric smoothing methods were used to obtain smoothed curves from the original log incidence data to reduce the observational error. The smooth curves are treated as functional observations with error.

$$
s_{t}(v)=\mu(v)+\sum_{k=1}^{K} \beta_{t, k} \phi_{k}(v)+e_{t}(v)
$$

Where $\mu(v)$ is the mean log incidence rate across years, $\phi_{k}(v)$ is a set of orthogonal basis functions, is a univariate time series, and the model error $e_{t}(v)$ assumed to be serially uncorrelated i.e. $e_{t}(v) \sim \mathrm{N}(0, v(v))$. Details are mentioned elsewhere [4].

\section{Log-linear regression (LLR) model}

Hakulinen and Dyba (1994) proposed a method for constructing prediction intervals with different models to calculate the number of cases and the age-specific incidence rates by assuming Poisson distribution for counts (number of cases) defined by age and sex [22]. This method can be applied to predict incidence cases based on a model with any functional form of linear predictor or link function [23, 27].

$$
\log E\left[y_{i t}\right]=\alpha_{i}+\beta_{i} t
$$

Here $E\left[y_{i t}\right]$ is the expected age-specific incidence rate of breast cancer in age group $i$, and time period $t$. Where $\alpha_{\mathrm{i}}$ is the baseline age-specific incidence rate at time $=0$, and $\beta_{i}$ is the observed expected annual change in the breast cancer incidence for the age-group $i$.

\section{Forecast accuracy measures}

Further, forecast accuracy as well as performance of both fitted models was evaluated based on the errors obtained using out-of-sample forecast approach, previously applied by Hyndman RJ, and
Athanasopoulos [28]. This approach is widely used to evaluate forecasting performance and, in turn, guide the selection of an appropriate forecasting model. The accuracy of forecasts can only be determined by considering how well a model performs on new data that were not used when estimating the model [29]. For this purpose, we divided the observed data into two series. First series (training data) having the observed incidence rates from 2004 to 2011 which is used for estimating the parameters, and forecasting the next set of observations, from 2012 to 2015. Second series (test data) having the observed incidence rates from 2012 to 2015 , which is used to test the forecasted observations, produced using the training data.

Let $y_{t}$ denote the observed actual age-specific incidence rates at time $t(t=1,2, . ., n)$ and $f_{t}$ denote the h-step ahead forecasted age-specific incidence rates of $y_{t}$. Then the forecast error can be calculated by taking difference between the actual rates in the test data and the h-step ahead forecasts produced using the training data. It is defined as $e_{t}=y_{t}-f_{t}$. A model with small forecast errors (residuals) will give good forecasts. We have used the five forecast accuracy measures defined as:

$$
\begin{aligned}
& \text { Mean Error }(M E)=\text { mean }\left(e_{t}\right) \text {, where } e_{t}=y_{t}-f_{t} \\
& \text { Mean Absolute Error }(M A E)=\text { mean }\left(\left|e_{t}\right|\right) \\
& \quad=\frac{\sum_{i=1}^{n}\left|y_{t}-f_{t}\right|}{n}
\end{aligned}
$$

Root Mean Square Error $(R M S E)=\sqrt{\operatorname{mean}\left(e_{t}^{2}\right)}$

Mean Absolute Percentage Error (MAPE)

$$
=\operatorname{mean}\left(\left|p_{t}\right|\right)
$$

Where

$$
p_{t}=100 \times e_{t} / y_{t}
$$

$$
\text { Mean Absolute Scaled Error }(M A S E)=M A E / Q
$$

Where

$$
Q=\frac{1}{n-1} \sum_{j=2}^{n}\left|y_{j}-f_{j-1}\right|
$$

Furthermore, annual changes in the age-specific incidence were calculated using estimated breast cancer cases from FTS model. The changes in incidence were computed as the difference between the predicted incidence for future years (2020 and 2025) and the observed cases for the year 2015. 


\section{Ethical considerations}

Formal written approval from hospital administration was obtained regarding use of anonymized and de-identified medical records. Consent to participate was not applicable to this study which was a secondary analysis of de-identified retrospective medical records. Further, none of the researchers had access to identifying information. The study was approved by the Institutional Review Board of the Jinnah Postgraduate Medical Centre, Karachi, Pakistan. (Reference Number: F.2-81/2014GENL/3434/JPMC).

\section{Results}

Table 1 shows the estimated population (persons per year) of female for 2004 to 2025 by each age group. The proportion of the female population in Karachi was estimated to be increasing in each age group with a slower increase in older ages ( $\geq 60$ years) with the time. The estimates revealed a total female population of over 7 million in year 2017 which nearly equals the newly released provisional figures of census 2017 at national level [16].

Table 2 shows past and future trends of age-specific breast cancer incidence rates. For past trends (20042015), breast cancer rates were considerably lower and stable in ages 15 to 29 years, while the incidence rates for women aged 25 years and older have been increasing overall with slight variations. Women aged 60-64 years had the highest overall breast cancer incidence rates through the years 2004-2015.

For the next 10 years and according to the predictions of the FTS model, predictions from FTS model, large increases in breast cancer rates among women aged 50 to 64 years are expected, while low increase in rates are expected among women of other ages. Specifically, the rate for women aged 55-59 years showed the highest overall breast cancer incidence, followed by women aged 50-54 and 60-64 years. Whereas LLR model predictions revealed that women older than age 75 years are at higher risk of breast cancer, followed by those women aged between 55 and 64 years. Dramatic decrease in rates was predicted among women aged 30-39 years, and rates should be considerably stable among ages $15-29$ years. Future incidence trends with comparison to past trends were also depicted in Additional file 1.

Past and future burden of age-specific breast cancer cases for the years 2004 to 2025 showed in Table 3. Future estimates of breast cancer cases were computed by multiplying estimates of breast cancer incidence rates and risk population for each age group. For past trends, during the study period (2004-2015), there were large increases in annual age-specific breast cancer cases for middle ages, considerable increases were observed among women aged 40-54 years.

Similar trends were observed for predicted cases for the next 10 years (2016-2025). The combined observed cases had increased from 1192 cases in 2004-2005 to 2495 cases in 2014-2015 (more than twice), and the expected cases of breast cancer are predicted to increase 4101 (FTS) / 4569 (LLR) cases in 2024-2025. For the next 10 years (from 2014 to 2015), future average annual breast cancer incidence increased 1.6 fold-FTS (1.8 foldLLR). Absolute numbers of breast cancer cases for each age group were predicted to increase except among younger ages, 15 to 19 years. Highest breast cancer burden was observed for women aged 40-44 years, predicted breast cancer cases increased from 440 in 201415 to 857 in 2024-2025 (1.9 fold increase-LLR). Increasing cases were noticeable for women aged 40 years and

Table 1 The trends in the age-specific population estimates among women-Karachi Pakistan (2004-2025)

\begin{tabular}{|c|c|c|c|c|c|c|c|c|c|c|c|}
\hline $\begin{array}{l}\text { Age-groups (in } \\
\text { years) }\end{array}$ & $\begin{array}{l}2004- \\
2005\end{array}$ & $\begin{array}{l}2006- \\
2007\end{array}$ & $\begin{array}{l}2008- \\
2009\end{array}$ & $\begin{array}{l}2010- \\
2011\end{array}$ & $\begin{array}{l}2012- \\
2013\end{array}$ & $\begin{array}{l}2014- \\
2015\end{array}$ & $\begin{array}{l}2016- \\
2017\end{array}$ & $\begin{array}{l}2018- \\
2019\end{array}$ & $\begin{array}{l}2020- \\
2021\end{array}$ & $\begin{array}{l}2022- \\
2023\end{array}$ & $\begin{array}{l}2024- \\
2025\end{array}$ \\
\hline $15-19$ & 1350496 & 1448418 & 1553440 & 1666077 & 1786881 & 1916445 & 2055402 & 2204436 & 2364276 & 2535705 & 2719564 \\
\hline $20-24$ & 1170251 & 1265186 & 1367821 & 1478782 & 1598744 & 1728438 & 1868654 & 2020244 & 2184131 & 2361314 & 2552870 \\
\hline $25-29$ & 923232 & 988196 & 1057730 & 1132158 & 1211823 & 1297093 & 1388364 & 1486056 & 1590622 & 1702547 & 1822347 \\
\hline $30-34$ & 768622 & 817785 & 870093 & 925746 & 984958 & 1047958 & 1114989 & 1186306 & 1262184 & 1342917 & 1428813 \\
\hline $35-39$ & 577176 & 600731 & 625247 & 650764 & 677321 & 704964 & 733734 & 763678 & 794844 & 827283 & 861044 \\
\hline $40-44$ & 527041 & 550750 & 575523 & 601411 & 628465 & 656734 & 686276 & 717146 & 749405 & 783115 & 818341 \\
\hline $45-49$ & 386243 & 405235 & 425160 & 446066 & 467999 & 491011 & 515154 & 540485 & 567061 & 594943 & 624198 \\
\hline $50-54$ & 329060 & 344551 & 360771 & 377754 & 395536 & 414156 & 433651 & 454066 & 475441 & 497821 & 521256 \\
\hline $55-59$ & 223013 & 237277 & 252454 & 268601 & 285782 & 304061 & 323510 & 344202 & 366218 & 389643 & 414565 \\
\hline $60-64$ & 179442 & 185648 & 192068 & 198711 & 205583 & 212694 & 220049 & 227659 & 235533 & 243679 & 252107 \\
\hline $65-69$ & 111856 & 118536 & 125615 & 133116 & 141065 & 149488 & 158415 & 167874 & 177899 & 188523 & 199780 \\
\hline $70-74$ & 75748 & 78212 & 80754 & 83381 & 86092 & 88891 & 91782 & 94766 & 97848 & 101030 & 104315 \\
\hline 75 \& above & 76361 & 78216 & 80116 & 82062 & 84055 & 86097 & 88189 & 90330 & 92525 & 94772 & 97074 \\
\hline
\end{tabular}

Estimated population at risk expressed as persons per year 
Table 2 Past and future age-specific breast cancer incidence rate estimates (2004-2025)

\begin{tabular}{|c|c|c|c|c|c|c|c|c|c|c|c|c|c|c|c|c|}
\hline \multirow{2}{*}{$\begin{array}{l}\text { Age- } \\
\text { groups } \\
\text { (in } \\
\text { years) }\end{array}$} & \multicolumn{6}{|c|}{ Observed Incidence Rates (2004-2015) } & \multicolumn{5}{|c|}{ Functional Time Series Model } & \multicolumn{5}{|c|}{ Log-Linear Regression Model } \\
\hline & $\begin{array}{l}2004- \\
2005\end{array}$ & $\begin{array}{l}2006- \\
2007\end{array}$ & $\begin{array}{l}2008- \\
2009\end{array}$ & $\begin{array}{l}2010- \\
2011\end{array}$ & $\begin{array}{l}2012- \\
2013\end{array}$ & $\begin{array}{l}2014- \\
2015\end{array}$ & $\begin{array}{l}2016- \\
2017\end{array}$ & $\begin{array}{l}2018- \\
2019\end{array}$ & $\begin{array}{l}2020- \\
2021\end{array}$ & $\begin{array}{l}2022- \\
2023\end{array}$ & $\begin{array}{l}2024- \\
2025\end{array}$ & $\begin{array}{l}2016- \\
2017\end{array}$ & $\begin{array}{l}2018- \\
2019\end{array}$ & $\begin{array}{l}2020- \\
2021\end{array}$ & $\begin{array}{l}2022- \\
2023\end{array}$ & $\begin{array}{l}2024- \\
2025\end{array}$ \\
\hline $15-19$ & 1.2 & 0.5 & 0.4 & 0.4 & 0.3 & 0.3 & 0.6 & 0.6 & 0.6 & 0.6 & 0.6 & 0.2 & 0.2 & 0.2 & 0.0 & 0.0 \\
\hline $20-24$ & 3.1 & 2.4 & 2.6 & 2.6 & 3.3 & 4.2 & 3.6 & 3.8 & 4.0 & 4.1 & 4.3 & 4.1 & 4.4 & 4.7 & 5.1 & 5.6 \\
\hline $25-29$ & 10.4 & 10.8 & 11.3 & 10.4 & 13.9 & 14.4 & 14.4 & 15.2 & 16.2 & 17.0 & 17.8 & 14.4 & 15.3 & 16.2 & 17.3 & 18.3 \\
\hline 30-34 & 23.1 & 21.2 & 23.7 & 21.8 & 30.7 & 33.1 & 38.4 & 40.9 & 43.5 & 46.2 & 48.9 & 31.9 & 34.5 & 37.5 & 40.6 & 43.9 \\
\hline $35-39$ & 62.8 & 50.3 & 55.8 & 48.6 & 69.9 & 81.4 & 75.7 & 81.0 & 86.4 & 92.0 & 97.6 & 74.3 & 78.9 & 83.8 & 89.0 & 94.4 \\
\hline $40-44$ & 72.2 & 70.5 & 80.4 & 74.5 & 99.1 & 134.0 & 119.3 & 127.8 & 136.7 & 145.7 & 154.9 & 129.5 & 146.0 & 164.6 & 185.6 & 209.3 \\
\hline $45-49$ & 90.6 & 90.9 & 100.8 & 95.9 & 121.8 & 154.2 & 159.5 & 171.1 & 182.8 & 194.7 & 206.8 & 146.7 & 162.1 & 179.2 & 198.0 & 218.9 \\
\hline $50-54$ & 102.7 & 114.2 & 117.7 & 108.0 & 143.8 & 169.4 & 187.7 & 201.0 & 214.4 & 228.0 & 241.6 & 154.9 & 167.9 & 181.9 & 197.0 & 213.5 \\
\hline 55-59 & 94.7 & 105.5 & 130.5 & 103.7 & 149.0 & 186.6 & 198.3 & 211.8 & 225.3 & 238.8 & 252.2 & 189.3 & 213.4 & 240.7 & 271.4 & 306.0 \\
\hline $60-64$ & 114.8 & 122.8 & 155.3 & 141.9 & 156.6 & 202.1 & 191.3 & 203.6 & 215.7 & 227.8 & 239.7 & 206.1 & 227.8 & 251.7 & 278.2 & 307.5 \\
\hline $65-69$ & 107.1 & 109.6 & 111.4 & 88.8 & 116.2 & 156.5 & 170.9 & 180.9 & 190.8 & 200.6 & 210.2 & 139.5 & 148.2 & 157.3 & 167.1 & 177.4 \\
\hline 70-74 & 95.1 & 99.5 & 99.2 & 129.4 & 155.7 & 152.8 & 142.9 & 150.4 & 157.8 & 164.8 & 171.9 & 177.1 & 198.8 & 223.3 & 250.8 & 281.6 \\
\hline $\begin{array}{l}75 \text { \& } \\
\text { above }\end{array}$ & 23.6 & 61.3 & 72.4 & 109.6 & 85.7 & 113.8 & 124.7 & 130.9 & 136.7 & 142.4 & 148.0 & 150.4 & 185.2 & 228.0 & 280.8 & 345.7 \\
\hline
\end{tabular}

Age-specific breast cancer incidence rates per 100,000 persons per year

above, incidence for women aged $40-59$ years have increased to 1454 in 2014-15 to 2432 (2731-LLR) cases by 2024-2025. Data showed in detail in Table 3.

Forecast accuracy as well as the comparison between the two models fitted to predict the incidence rates, are shown in Table 4, indicating that FTS model is giving small absolute errors as compared to measures computed with the LLR model. This shows that FTS model performed better and gives good forecasts than the other fitted model. Further, forecasting performance across ages for both models was also assessed, and results showed similar forecast variations for ages 20 to 59, however, absolute differences in both models were observed in predicted values for older ages (60 and above). [See Additional file 1: Table S1 and S2].

Table 5 presents the annual changes in breast cancer incidence in 2020 and 2025 relative to 2015, among all age groups. Between 2015 and 2020, the largest increase

Table 3 Past and future predicted age-specific breast cancer incidence estimates (2004-2025)

\begin{tabular}{|c|c|c|c|c|c|c|c|c|c|c|c|c|c|c|c|c|}
\hline \multirow{2}{*}{$\begin{array}{l}\text { Age- } \\
\text { groups } \\
\text { (in } \\
\text { years) }\end{array}$} & \multicolumn{6}{|c|}{ Observed Incidence (2004-2015) } & \multicolumn{5}{|c|}{ Functional Time Series Model } & \multicolumn{5}{|c|}{ Log-Linear Regression Model } \\
\hline & $\begin{array}{l}2004- \\
2005\end{array}$ & $\begin{array}{l}2006- \\
2007\end{array}$ & $\begin{array}{l}2008- \\
2009\end{array}$ & $\begin{array}{l}2010- \\
2011\end{array}$ & $\begin{array}{l}2012- \\
2013\end{array}$ & $\begin{array}{l}2014- \\
2015\end{array}$ & $\begin{array}{l}2016- \\
2017\end{array}$ & $\begin{array}{l}2018- \\
2019\end{array}$ & $\begin{array}{l}2020- \\
2021\end{array}$ & $\begin{array}{l}2022- \\
2023\end{array}$ & $\begin{array}{l}2024- \\
2025\end{array}$ & $\begin{array}{l}2016- \\
2017\end{array}$ & $\begin{array}{l}2018- \\
2019\end{array}$ & $\begin{array}{l}2020- \\
2021\end{array}$ & $\begin{array}{l}2022- \\
2023\end{array}$ & $\begin{array}{l}2024- \\
2025\end{array}$ \\
\hline 15-19 & 8 & 4 & 3 & 4 & 3 & 3 & 6 & 6 & 6 & 7 & 8 & 2 & 2 & 2 & 2 & 0 \\
\hline $20-24$ & 18 & 15 & 18 & 19 & 27 & 36 & 35 & 39 & 43 & 49 & 55 & 38 & 44 & 52 & 61 & 71 \\
\hline $25-29$ & 48 & 53 & 59 & 59 & 84 & 93 & 101 & 113 & 128 & 144 & 163 & 100 & 114 & 130 & 147 & 167 \\
\hline $30-34$ & 89 & 87 & 103 & 101 & 152 & 173 & 214 & 243 & 275 & 310 & 350 & 178 & 205 & 236 & 272 & 315 \\
\hline $35-39$ & 181 & 151 & 174 & 158 & 237 & 287 & 278 & 310 & 343 & 380 & 420 & 273 & 301 & 333 & 368 & 406 \\
\hline $40-44$ & 190 & 194 & 231 & 224 & 312 & 440 & 410 & 459 & 512 & 571 & 634 & 444 & 524 & 617 & 727 & 857 \\
\hline $45-49$ & 175 & 184 & 214 & 214 & 286 & 379 & 411 & 462 & 518 & 580 & 645 & 378 & 438 & 509 & 590 & 683 \\
\hline $50-54$ & 169 & 197 & 212 & 204 & 285 & 351 & 407 & 457 & 510 & 567 & 630 & 336 & 382 & 432 & 491 & 556 \\
\hline $55-59$ & 106 & 125 & 164 & 139 & 213 & 284 & 321 & 365 & 413 & 466 & 523 & 306 & 367 & 441 & 529 & 635 \\
\hline $60-64$ & 103 & 114 & 149 & 141 & 161 & 215 & 211 & 232 & 254 & 278 & 302 & 227 & 259 & 296 & 339 & 387 \\
\hline $65-69$ & 60 & 65 & 70 & 59 & 82 & 117 & 136 & 152 & 170 & 189 & 210 & 111 & 124 & 140 & 157 & 177 \\
\hline $70-74$ & 36 & 39 & 40 & 54 & 67 & 68 & 65 & 71 & 77 & 83 & 90 & 81 & 94 & 110 & 127 & 147 \\
\hline $\begin{array}{l}75 \& \\
\text { above }\end{array}$ & 9 & 24 & 29 & 45 & 36 & 49 & 55 & 59 & 63 & 67 & 71 & 66 & 83 & 106 & 133 & 168 \\
\hline
\end{tabular}


Table 4 Accuracy measures of the models computed from test data

\begin{tabular}{llllll}
\hline Model & ME & MAE & RMSE & MAPE & MASE \\
\hline FTS & 12.3 & 13.5 & 17.3 & 29.2 & 1.0 \\
LLR & 6.7 & 15.7 & 21.5 & 33.7 & 1.2 \\
\hline
\end{tabular}

FTS Functional time series, LLR Log-linear regression, ME Mean error, MAE Mean absolute error, RMSE Root mean square error, MAPE Mean absolute percentage error, MASE Mean absolute scaled error

in breast cancer incidence is expected among younger women aged less than 34 years $(70.7 \%$ for women aged 30-34 years). Whereas, women aged 30-34 years may be responsible for a 130.6\% increase in incidence by 2025 . The incidence for all ages is predicted to increase from 1309 in 2015 to 1611 (23.1\% increased) in 2020 and 2103 in 2025 , which is $60.7 \%$ higher than the incidence in 2015.

\section{Discussion}

This paper presents past and future estimates of breast cancer incidence rates and expands our understanding of age and time related differences in incidence rate of breast cancer among women of Karachi, Pakistan. The cancer statistics from Karachi potentially reflect national level picture, because it is the only city of Pakistan which is composed of considerable population from various ethnic groups. Therefore, in the absence of a national level cancer registration process, medical records from hospitals in Karachi can be considered as highly representative of Pakistani population [30].
Prior studies from the region have highlighted increase in breast cancer burden among women in Pakistan [17, 30-32], however none of these studies applied statistical modeling and moreover, these studies were based on cross-sectional data. In this study, we assessed two models and report for the first time comparison of these approaches to incidence prediction of breast cancer in Pakistani females for the period of 2016-2025, as well as with the focus on testing the reliability of the methods. We show increasing breast cancer trend during 2004 to 2015, and we expect the trend will continue to rise in the future, particularly during the period 2016-2025. However, the age-specific breast cancer incidence rates are found heterogeneous. Between 2004 and 2015, overall incident rates were highest among women aged 6064 years while from 2016 to 2025 large increases in breast cancer rates among women aged 55 to 64 years and women older than age 75 years are expected. Nevertheless, the overall breast cancer incidence appeared to be rising more rapidly among post-menopausal women, while a stable increase in incidence in youngest age group of women aged 15-29 years was observed. The results also infer an increase in incidence rate of elderly breast cancer similar to the patterns observed among women in developed countries [1, 8, 33].

In the present study, we expect the number of breast cancer cases to increase by $60.7 \%$ (approximately to 2103 to be diagnosed by 2025). Although, past trend of breast cancer cases among elderly women (aged 65 and above) were rare compared to women aged 60 to 64 years, but these would become common in 2021-2025.

Table 5 FTS-\% change in age-specific breast incidence 2015-2025

\begin{tabular}{|c|c|c|c|c|c|}
\hline \multirow{3}{*}{$\begin{array}{l}\text { Age- } \\
\text { groups }\end{array}$} & \multicolumn{5}{|c|}{ Annual changes in breast cancer incidence compared with 2015} \\
\hline & \multirow{2}{*}{$\begin{array}{l}2015 \\
\text { Cases }\end{array}$} & \multicolumn{2}{|l|}{2020} & \multicolumn{2}{|l|}{2025} \\
\hline & & Difference & $\%$ & Difference & $\%$ \\
\hline $15-19$ & 2 & 1 & 57.8 & 2 & 99.0 \\
\hline $20-24$ & 16 & 5 & 31.5 & 12 & 76.7 \\
\hline $25-29$ & 41 & 21 & 51.7 & 43 & 104.5 \\
\hline $30-34$ & 78 & 55 & 70.7 & 102 & 130.6 \\
\hline $35-39$ & 150 & 17 & 11.6 & 65 & 43.6 \\
\hline $40-44$ & 231 & 18 & 7.9 & 94 & 40.7 \\
\hline $45-49$ & 209 & 43 & 20.5 & 122 & 58.5 \\
\hline $50-54$ & 190 & 58 & 30.5 & 133 & 69.9 \\
\hline $55-59$ & 153 & 47 & 30.7 & 116 & 75.8 \\
\hline 60-64 & 116 & 8 & 7.0 & 38 & 33.0 \\
\hline $65-69$ & 60 & 23 & 37.6 & 48 & 79.5 \\
\hline 70-74 & 38 & 0 & -0.4 & 8 & 20.1 \\
\hline 75 \& above & 25 & 6 & 24.4 & 11 & 45.8 \\
\hline Total & 1309 & 302 & 23.1 & 794 & 60.7 \\
\hline
\end{tabular}

Age-specific breast cancer cases per 100,000 persons per year 
The volume of pre-menopausal cases (aged 40 to 44 years) would increase from $7.9 \%$ in 2020 to $40.7 \%$ in 2025. Compared to pre-menopausal women, the projected increase in breast cancer cases among post-menopausal women (aged 55 to 59) is relatively higher (from 30.7 to $75.8 \%$ in 2020 and 2025). Even though, the incidence among younger age groups is very low, but these results may reflect less screening efforts targeting this age group. Therefore, the reported breast cancer burden may be underestimated. The lack of specialized care units and the weak data bases in Pakistan contribute to the reported lower incidences [34]. Many women would have to be screened to find the cases, thus we suggest greater awareness on early signs of breast cancer among younger women and education on breast self-examination to realize early detection among the younger age groups.

The predicted values from the applied models showed gradual and uniform increase in the incidence of breast cancer over the study period (i.e. during 2004-2025) in Pakistan (See Additional file 1: Figure S1 and S2).

Breast cancer incidence remain highest in the age group of 60 to 64 during 2004 to 2015 but the FTS estimates showed the shift in maximum rate of incidence in the age group of 55 to 59 . While, according to LLR predictions same age group (i.e. 55 to 59 years) will experience highest incidence till 2025. Moreover, FTS model showed small absolute errors than other predicted model. This indicates that the forecasting performance of FTS model in predicting incidence rates was better compared to the LLR model. Earlier epidemiological studies from Asian and Western countries have presented notable difference in peak incidence, which was between 40 to 50 years in Asian women whereas the peak incidence was between 60 to 70 years in Western women [35-37]. We found not only increase in age-specific incidence rate in Pakistani women but also predicted the peak age of onset continuing in postmenopausal women which is somewhat similar to the incidence reported from other Western type data $[9,35]$. The reduction in variation observed in peak onset age between western countries and our population is most likely attributable to rise in urbanized and westernized culture in our society $[15,36]$. However, we need more researches to determine similarities and differences in breast cancer among women from Asian countries to compare with diverse global populations with different geographic, racial/ethnic, genetic, lifestyle and socioeconomic backgrounds.

The demographic component underlying the increasing future burden of breast cancer is likely to continue as Pakistan population is expected to increase, with the largest increases expected in population aged 15-64. Although, the population under 40 years, except the young adolescent age, is rising at a slower rate; high fertility will remain one of the key forces contributing to further population growth. In contrast, the population of 65-74 years is small but growing. As a result, rapid population aging and increase in working age women is now taking place [38]. Under such conditions, breast cancer incidence rate and the age structure of women with breast cancer will change with time.

With this, the rise in incidence of breast cancer also reflects noticeable changes in distribution of risk factors associated with shifts in life style and changing socioeconomic development $[35,36]$. There is evidence that increase in adoption of cancer associated lifestyle choices including smoking, physical inactivity, and "westernized" diets are emerging risk factors for breast cancer incidence in the region [39]. Another study reported illiteracy, cultural and economic hindrance as reasons for late consultation of medical physician [40]. These factors have important implications for stage presentation at diagnosis and highlight an immediate attention for early detection strategies and cheap access to healthcare provision. In addition, accurate projections of agespecific breast cancer incidence may prove to be helpful, particularly for the planning and implementation of mammographic screening programs. In this regard, both models performed rather similarly, but the FTS model worked slightly better than LLR model. This could be probably because the FTS models take age as a continuous function, which allows capturing the subtle patterns of variation between years. Thus; reduced the observational error by use of smoothed data before beginning the estimation of basic functions [21, 26]. However, the second approach, LLR model, is used with the assumption that the observations either age or period specific incidence cases must be independent and follow Poisson distributions [22]. Since the actual projection period in the current study is short (10 years, 2016-2025), we used only the log-linear regression model, rather than models more appropriate for increasing rates that specify an identity link function [27].

This study has a number of important strengths. First, we have presented an alternative modelling approach for estimation of breast cancer incidence, thereby enhancing the accuracy of the prediction intervals for future incidence rates. Further, these models will be most useful for modeling and projecting the future trends of other cancers as well, for which there has been very little advancement in treatment and opportunities for prevention, early detection, or both, are few. While we have made an attempt to provide a robust estimation of past and future age-specific breast cancer incidence, we are aware that there are some limitations to this study. First, our study lacks inclusion of birth cohort effect, breast cancer subtype information and other important risk 
factors such as screening and treatment options associated with hormone replacement therapy that may influence age-related changes in incidence. Currently FTS model do not incorporate such effects, but smoothing process used in FTS modelling may reduce the variation attributable to such effects [26]. It is likely that improving prediction models will require inclusion of additional known risk factors which may play a large role in the surveillance, treatment, and survival outcomes of this disease [21]. Future studies are suggested to incorporate these detail assessments to provide a more comprehensive understanding of breast cancer temporal patterns in Pakistan. Secondly, there is a possibility/limitation that there are more breast cancer cases in the city than described herein. Those could potentially include patients who do not have access to hospitals and/or that are diagnosed at other health facility. It could happen that these patients were the most economically disadvantaged. However, our data is based on the largest possible registries of the city, thus serving as the major source in breast cancer data in Karachi, and thereby allowing better estimates of national pattern in the absence of any population based cancer registry in the country [17, 41]. Therefore we recommend that the health system should emphasize on gathering nationwide formal cancer registry data to facilitate efficient planning of research to reduce breast cancer burden as well planning of future cancer services.

\section{Conclusions}

In conclusion, this analysis demonstrates increase in the number of incident cases of breast cancer in Pakistani women. The breast cancer incidence appeared to be rising more rapidly among post-menopausal women, while a stable increase in incidence among youngest age group of women are expected. The age-specific patterns of breast cancer incidence in Pakistan are in line with other countries in Asia, however the shift in maximum rate of breast cancer incidence in the age group of 55 to 59 was observed.

\section{Additional file}

Additional file 1 : Microsoft Word file (doc) providing details of the supplementary figures and tables. (DOCX $2520 \mathrm{~kb}$ )

\footnotetext{
Abbreviations

ASGR: Age-Specific Growth Rate; CHK: Civil Hospital Karachi; FTS: Functional Time Series; JPMC: Jinnah Post Graduate Medical Centre; KIRAN: Karachi Institute of Radiotherapy and Nuclear Medicine; LLR: Log-Linear Regression; MAE: Mean Absolute Error; MAPE: Mean Absolute Percentage Error; MASE: Mean Absolute Scaled Error; ME: Mean Error; RMSE: Root Mean Square Error
}

\section{Acknowledgments}

The authors are deeply thankful to the oncology data units for their help and cooperation in providing the data information. Authors are deeply thankful to Ms. Saba Mughal for providing support in data approvals and collection.

\section{Authors' contributions}

$\mathrm{SZ}$ conceived the idea of the work, run the statistical analysis and wrote the first draft with NS who also contributed in data interpretation; SAM and NMS monitored the data indexation. All the authors contributed to the writing of the manuscript. All authors read and approved the final manuscript.

\section{Funding}

None.

\section{Availability of data and materials}

Data included in the current study are not publicly available to ensure confidentiality of the patients but are available from the corresponding author on reasonable request. However, all data generated or analysed during this study are included in this published article.

\section{Ethics approval and consent to participate}

Formal written approval from hospital administration was obtained regarding use of anonymized and de-identified medical records. Consent to participate was not applicable to this study which was a secondary analysis of de-identified retrospective medical records. Further, none of the researchers had access to identifying information. The study was approved by the Institutional Review Board of the Jinnah Postgraduate Medical Centre, Karachi, Pakistan. (Reference Number: F.2-81/2014-GENL/3434/JPMC).

\section{Consent for publication}

Not applicable.

\section{Competing interests}

The authors declare that they have no competing interests.

\section{Author details}

${ }^{1}$ Department of Statistics, University of Karachi, Karachi, Pakistan. ${ }^{2}$ School of Public Health, Dow University of Health Sciences, OJHA Campus, Suparco road, Karachi, Pakistan. ${ }^{3}$ Department of Clinical Oncology, Karachi Institute of Radiotherapy and Nuclear Medicine, Karachi, Pakistan. ${ }^{4}$ Oncology Department, Civil Hospital, Karachi, Pakistan.

Received: 3 April 2019 Accepted: 16 July 2019

Published online: 25 July 2019

\section{References}

1. Bray F, Ferlay J, Soerjomataram I, Siegel RL, Torre LA, Jemal A. Global cancer statistics 2018: GLOBOCAN estimates of incidence and mortality worldwide for 36 cancers in 185 countries. CA Cancer J Clin. 2018;68(6):394-424.

2. Fitzmaurice C, Allen C, Barber RM, Barregard L, Bhutta ZA, Brenner H, et al. Global, regional, and national cancer incidence, mortality, years of life lost, years lived with disability, and disability-adjusted life-years for 32 cancer groups, 1990 to 2015: a systematic analysis for the global burden of disease study. JAMA Oncol. 2017;3(4):524-48.

3. Sohail S, Alam SN. Breast cancer in Pakistan - awareness and early detection. J Coll Physicians Surg Pak. 2007;17(12):711-2.

4. Yasmeen F, Zaheer S. Functional time series models to estimate future agespecific breast Cancer incidence rates for women in Karachi, Pakistan. J Health Sci. 2014;2(5):213-21.

5. Begum N. Breast Cancer in Pakistan: A Looming Epidemic. J Coll Physicians Surg Pak. 2018;28(2):87-8. https://doi.org/10.29271/jcpsp.2018.02.87.

6. Hanif M, Sabeen B, Maqbool A, Ahmed A, Nadeem F, Habib S. Breast cancer: incidence (thirteen year data analysis) and one year clinicopathological data of patients in a tertiary care cancer hospital. Int J Biol Biotechnol. 2015;12(3): 373-9.

7. Carroll PS, Utshudiema JS, Rodrigues J. The British breast cancer epidemic: trends, patterns, risk factors, and forecasting. J Am Physicians Surg. 2017; 22(1):8-16. 
8. Toyoda Y, Tabuchi T, Nakayama T, Hojo S, Yoshioka S, Maeura Y. Past trends and future estimation of annual breast Cancer incidence in Osaka, Japan. Asian Pac J Cancer Prev. 2016;17(6):2847-52.

9. Mathew A, George P, Arjunan A, Augustine P, Kalavathy M, Padmakumari G, et al. Temporal trends and future prediction of breast Cancer incidence across age groups in Trivandrum, South India. Asian Pac J Cancer Prev. 2016;17(6):2895-9.

10. Park EH, Min SY, Kim Z, Yoon CS, Jung K-W, Nam SJ, et al. Basic facts of breast cancer in Korea in 2014: the 10-year overall survival progress. J Breast Cancer. 2017;20(1):1-11.

11. Fernando A, Jayarajah U, Prabashani S, Fernando EA, Seneviratne SA. Incidence trends and patterns of breast cancer in Sri Lanka: an analysis of the national cancer database. BMC Cancer. 2018;18(1):482

12. Qureshi MA, Mirza T, Khan S, Sikandar B. Cancer registration in Pakistan: a dilemma that needs to be resolved. Int J Cancer. 2015;136(6):E773. https:// doi.org/10.1002/ijc.29253 Epub 2014 Oct 18.

13. Mariotto AB, Robin Yabroff K, Shao Y, Feuer EJ, Brown ML. Projections of the cost of cancer care in the United States: 2010-2020. J Natl Cancer Inst. 2011; 103(2):117-28

14. Maddams J, Utley M, Møller $\mathrm{H}$. Projections of cancer prevalence in the United Kingdom, 2010-2040. Br J Cancer. 2012:107(7):1195.

15. Yu XQ, De Angelis R, Luo Q, Kahn C, Houssami N, O'Connell DL. A population-based study of breast cancer prevalence in Australia: predicting the future health care needs of women living with breast cancer. BMC Cancer. 2014;14(1):936

16. Pakistan Buraeu of Statistics GoP. Distribution of districts. http://www.pbs. gov.pk/content/population-census. Accessed 15 Jan 2019.

17. Hanif M, Zaidi P, Kamal S, Hameed A. Institution-based cancer incidence in a local population in Pakistan: nine year data analysis. Asian Pac J Cancer Prev. 2009;10(2):227-30.

18. Feeney G, Alam I. New estimates and projections of population growth in Pakistan. Popul Dev Rev. 2003;29(3):483-92.

19. Wilson T. New evaluations of simple models for small area population forecasts. Popul Space Place. 2015;21(4):335-53.

20. Dicker RC, Coronado F, Koo D, Parrish RG. Principles of epidemiology in public health practice; an introduction to applied epidemiology and biostatistics. Atlanta: U.S. Department of Health and Human Services, Centers for Disease Control and Prevention (CDC), Office of Workforce and Career Development. Atlanta 30333;2006.

21. Yasmeen F, Hyndman RJ, Erbas B. Forecasting age-related changes in breast cancer mortality among white and black US women: a functional data approach. Cancer Epidemiol. 2010;34(5):542-9.

22. Hakulinen T, Dyba T. Precision of incidence predictions based on Poisson distributed observations. Stat Med. 1994;13(15):1513-23.

23. Yang L, Parkin D, Li L, Chen Y, Bray F. Estimation and projection of the national profile of cancer mortality in China: 1991-2005. Br J Cancer. 2004; 90(11):2157.

24. Hyndman RJ, Ullah MS. Robust forecasting of mortality and fertility rates: a functional data approach. Comput Stat Data Anal. 2007;51(10):4942-56.

25. Erbas B, Hyndman RJ, Gertig DM. Forecasting age-specific breast cancer mortality using functional data models. Stat Med. 2007;26(2):458-70.

26. Erbas B, Akram M, Gertig DM, English D, Hopper JL, Kavanagh AM, et al. Using functional data analysis models to estimate future time trends in age-specific breast cancer mortality for the United States and England-Wales. J Epidemiol. 2010;20(2):159-65.

27. Dyba T, Hakulinen T. Comparison of different approaches to incidence prediction based on simple interpolation techniques. Stat Med. 2000;19(13):1741-52.

28. Hyndman RJ, Athanasopoulos G. Forecasting: principles and practice. 2nd ed. Melbourne: OTexts; 2018.

29. Hyndman RJ, Koehler AB. Another look at measures of forecast accuracy. Int J Forecast. 2006;22(4):679-88.

30. Qureshi MA, Mirza T, Khan S, Sikandar B, Zahid M, Aftab M, et al. Cancer patterns in Karachi (all districts), Pakistan: first results (20102015) from a pathology based cancer registry of the largest government-run diagnostic and reference center of Karachi. Cancer Epidemiol. 2016:44:114-22.

31. Mahmood S, Faraz R, Yousaf A, Asif H, Badar F. Cancer Registry and Clinical Data Management (CRCDM) - Shaukat Khanum Memorial Cancer Hospital and Research Center (SKMCH \& RC) - Report Based on Cancer Cases Registered at SKMCH \& RC from December 1994-December 2014 and in 2014. Released June. 2015.
32. Basra M, Saher M, Athar MM, Raza MH. Breast cancer in Pakistan a critical appraisal of the situation regarding female health and where the nation stands? Asian Pac J Cancer Prev. 2016;17(7):3035-41.

33. Youlden DR, Cramb SM, Dunn NA, Muller JM, Pyke CM, Baade PD. The descriptive epidemiology of female breast cancer: an international comparison of screening, incidence, survival and mortality. Cancer Epidemiol. 2012;36(3):237-48.

34. Hadi MA, Madani AR, Abu Arida L, Al Ghareeb B. Breast Cancer Age in Developing Countries: The Narrowing Gap. Clin Surg. 2018;3:2074.

35. Leong SP, Shen Z-Z, Liu T-J, Agarwal G, Tajima T, Paik N-S, et al. Is breast cancer the same disease in Asian and Western countries? World J Surg. 2010;34(10):2308-24.

36. Ginsburg O, Bray F, Coleman MP, Vanderpuye V, Eniu A, Kotha SR, et al. The global burden of women's cancers: a grand challenge in global health. Lancet. 2017:389(10071):847-60.

37. Ferlay J, Soerjomataram I, Dikshit R, Eser S, Mathers C, Rebelo M, et al. Cancer incidence and mortality worldwide: sources, methods and major patterns in GLOBOCAN 2012. Int J Cancer. 2015;136(5):E359-E86.

38. Bongaarts J, Sathar ZA, Mahmood A. Population trends in Pakistan. Popul Counc Book Ser. 2013;1(1):13-23.

39. Jemal A, Bray F, Center MM, Ferlay J, Ward E, Forman D. Global cancer statistics. CA Cancer J Clin. 2011;61(2):69-90.

40. Mamoon N, Hassan U, Mushtaq S. Breast carcinoma in young women aged 30 or less in northern Pakistan - the armed forces Institute of Pathology experience. Asian Pac J Cancer Prev. 2009;10(6):1079-82.

41. Khokher S, Qureshi MU, Mahmood S, Sadiq S. Determinants of advanced stage at initial diagnosis of breast Cancer in Pakistan: adverse tumor biology vs delay in diagnosis. Asian Pac J Cancer Prev. 2016;17(2):759-65.

\section{Publisher's Note}

Springer Nature remains neutral with regard to jurisdictional claims in published maps and institutional affiliations.

Ready to submit your research? Choose BMC and benefit from:

- fast, convenient online submission

- thorough peer review by experienced researchers in your field

- rapid publication on acceptance

- support for research data, including large and complex data types

- gold Open Access which fosters wider collaboration and increased citations

- maximum visibility for your research: over $100 \mathrm{M}$ website views per year

At BMC, research is always in progress.

Learn more biomedcentral.com/submissions 